\title{
Using a Standard Reading Exercise in a Foundational Literacies Course
}

\author{
James Emmet Owens \\ Kanda University of International Studies, Chiba, Japan
}

\begin{abstract}
The benefits of a standard exercise, whereby students regularly answer the same set of questions by applying them to a variety of different texts, were first explored by Scott, Carioni, Zanatta, Bayer, and Quintanilha (1984). The Foundational Literacies Advanced Stream curriculum design project at a Japanese university has decided to experiment with such an exercise, as it is felt that introducing students to a range of different texts can be a useful method of learner empowerment. Students were given the opportunity to offer feedback on the activity in the form of a survey. Additionally, three students provided further comment in interviews. This paper attempts to justify the inclusion of such an exercise in the curriculum, explain the text choices, evaluate the relative success and usefulness of the experiment by analysing the results of the survey and interviews, and also to advise of any improvements that might need to be made.
\end{abstract}

Utilisation of a standard reading exercise (SRE) has long been advocated, for example by Scott, Carioni, Zanatta, Bayer, \& Quintanilha (1984) and more recently Paltridge (2002). Members of a curriculum design committee decided to implement its use in an Advanced Stream course for freshman students at a university near Tokyo, over the academic year 2013-2014. This paper will first explain the academic context for this decision, and then the design process. It will next justify the selection of texts, and finish by analysing both qualitative and quantitative data to consider the effectiveness of the exercise. The paper concludes that the SRE has been largely successful, and with some modifications will continue to be utilised. This paper is of possible interest to anyone involved in the teaching of reading. It contributes to a holistic understanding of the way learners acquire reading skills, in contrast to those understandings framed only by traditional views of literacy competency.

\section{Background}

\section{Literature Review}

Freshman students in the English department at a Japanese university take four 90-minute weekly communication skills classes, and two lessons of Foundational Literacies (FL). The course integrates reading and writing in a genre-based curriculum, and hopes to empower students by familiarizing them with a range of different text types. As Hyland (2007) wrote, "genre pedagogies" can help enable "learners to participate effectively in the world outside" of the school or institution (p. 148). A similar "genre-based approach" that pays close attention to both " the context of situation and the context of culture" (Chaisiri, 2010, p. 181) has been

Language Education in Asia, 2014, 5(1), 81-92. http://dx.doi.org/10.5746/LEiA/14/V5/I1/A07/Owens 
made use of in South East Asian countries such as Thailand and found to be effective when teaching writing skills.

It was deemed necessary to develop a regular homework activity for this Advanced Stream that would complement the course. It was decided to utilize a SRE, inspired largely by the work done in Brazil by Scott et al. (1984).

\section{What is a Standard Reading Exercise?}

Scott et al. (1984) feel that in order to stimulate students and make resources relevant, material designers must constantly find new and interesting texts for their students to read and answer questions about. This means having to design a new task for every new text, demanding too much time effort. Budgets can also be a constraint in this respect, for example in certain poor nations. Their suggested solution is to create "a 'standard exercise' (SE)" designed to be compatible "with virtually any text" (p. 114). The texts that students read constantly change, but the questions that accompany these readings remain unchanged. This also helps reduce cognitive demand on learners, especially when they are engaged with challenging material, as only one variable is changed - the text itself. Additionally, the use of an SE can lead the person assigning the work to possess "much greater freedom in text selection" (p. 114), thus granting learners access to as many different genres of text as possible.

\section{The Development of the Exercise}

In their SE, Scott et al. (1984) identify three different types of reading comprehension: "general," "main points," and "detailed" (p. 116). Their list of questions (see Appendix A) thus develops progressively from predicting activities (in order to activate schemata) "to deeper and more critical levels of comprehension" (p. 116). They also end the exercise with some evaluation and self-reflection exercises, as "reading without some sort of personal involvement" (p. 117) is essentially ineffective. They hoped the use of the SE would discourage students from "frustratingly frequent reference to the dictionary," and encourage them to focus more "on the main ideas" (p. 115) given it is likely impossible that they would be able to understand every small detail. Whilst Scott et al.'s SE was designed in the 1980s, this obsession with understanding every word would seem to remain a problem experienced by many learners, and perhaps this is especially true in Asia.

The SRE designed for use by the author (Appendix B) follows the same principle as that designed by Scott et al. (1984): one list of questions used repeatedly with a variety of different texts. Some questions are similar, and the overall shape of the exercise is analogous to the original: it begins with a "Predicting" section and finishes with a "Reflection."

However, it was also hoped the activity would aid "genre awareness" (Johns, 2008, p. 238). To aid learner empowerment and critical thinking, questions were set that focused more on the field, tenor, and mode of each text. The exercise encourages students to consider language choice, the "reader-in-the-text" (Thompson, 2012), i.e., the intended audience, authorial intention, structure, and organization, especially in the second and third parts of the exercise.

The SRE introduces non-linguistic elements, hence Part 2 encourages the creative use of image. This is based on a belief that doing so can afford a learner something that written language cannot, relating to Nelson's (2008) conjecture that second-language learners possess a greater need to make use of the "communicative potential of nonlinguistic resources" (p. 69). A detailed analysis of such non-linguistic elements will provide the basis for a future paper. 
The initial design resulted in an overlarge task to the point of being counter-productive, hence it was edited and condensed. This obviously compromises aspirations of the design, which is something to consider, but at this stage it was considered a priority to make the SRE as concise as possible.

\section{Text Selection}

The institution is encouraging students to study abroad, and has received a grant from the Japanese government to this end. One requirement is that students obtain high TOEFL scores; thus, it was necessary to include some test-style readings within the range of texts selected.

Aside from this one constraint, the committee wanted to make this range varied, agreeing with Scott et al.'s (1984) assertion that "there should be a wide choice of fresh and interesting texts" (p. 119). Familiarising students with many different text types empowers them, because in exposing students to a variety of different "contexts," the students can "learn a range of genres central to participation" in the creation of "political, social, and cultural realities (Byrnes, Crane, Maxim, \& Sprang, 2006, p. 89). In this aspect, the selection of texts followed the example of Byrnes et al. (2006) by integrating a range of texts, progressing from "familiar interactions" to "public, institutional, and professional settings" (p. 89).

Byrnes et al. (2006) define this as a "primary-secondary discourse continuum" (p. 93). "Primary discourses" comprise personal, experiential discourses such as blogs, email, or personal narratives. "Blurred discourses" are typically literary discourses such as narratives or poetry. "Secondary discourses" are more institutional public or academic discourses, for example, expository prose, popular science articles, or pamphlets.

More than twenty texts were selected that divided roughly equally into these categories, with some grey areas. These were set as weekly readings, with answers submitted the following week. Primary discourses were generally assigned first, followed by blurred and secondary. Where time permitted, students had opportunities to discuss their answers with each other during lesson time.

\section{How Successful was the SRE?}

At the end of the academic year, students completed an online survey. One multiple-choice question asked respondents to grade the usefulness of the SRE. There were 63 responses to this question (out of an approximate 120 students in total). The results can be seen below:

\section{Table 1}

Results of the survey as to how useful students found the SRE

\begin{tabular}{|l|c|c|}
\hline Usefulness & Responses (number) & Responses (\%) \\
\hline Not at all & 0 & $0.0 \%$ \\
\hline Not very & 1 & $1.6 \%$ \\
\hline No strong opinion & 12 & $19.0 \%$ \\
\hline Quite useful & 24 & $38.1 \%$ \\
\hline Very useful & 26 & $41.3 \%$ \\
\hline
\end{tabular}

They reveal responses were overwhelmingly positive, with no respondents regarding the SRE as "not at all useful." Almost $80 \%$ consider the exercise quite or very useful. The results seem congruent with Scott et al.'s (1984) conclusion, based on their own survey, that responses "confirmed the usefulness of the standard exercise as a teaching and practice procedure" (p. 
118).

However, given the limited number of responses (it could be assumed, for example, that only more motivated students responded), the inherent limitation of asking the subjects themselves what is useful, and the consideration that in general surveys are "not very reliable instruments" (Scott et al., 1984, p. 118), these results by themselves are not conclusive. It was decided that conducting interviews would provide further insight.

\section{Methodology}

The research took the form of a pilot study, and it was decided to simply focus on three students from one of the classes, from hereon to be referred to as Students A, B and C. Their answers to the SRE were collected throughout both semesters, and they were interviewed for approximately an hour each at the end of the academic year.

The research questions the interviewer hoped to answer in conducting these interviews were:

How effective is the SRE in complementing the goals of the FL (Advanced Stream) course? What effect does it have on students' reading ability?

What, if any, are the benefits of a repeated activity?

How can the SRE be improved for the future?

The interviewees were chosen by randomly selecting three volunteers. Arguably, volunteers are more likely to be highly motivated and thus provide perhaps unrepresentative responses. However, it was deemed important to only use willing students in a year that had been challenging for the freshman students. The reason it had been challenging was that this was the first year that the new course (with a more demanding workload than in previous years) designed especially for advanced-level students was implemented.

All three students were female freshmen (students at the university are approximately $75 \%$ female), aged 18-21, and from the same FL class. The interviews focused on just five texts: an email from a mother to her son's fiancé, a "spam" email asking for bank details, a recipe, a poem ("Thanksgiving Day Prayer" by William S. Burroughs) and a research article from the BBC website entitled "Kinder Children are More Popular." These texts were selected firstly as they cover all three of Byrnes et al.'s (2006) discourse types: primary, blurred, and secondary, and secondly as they generated the most interesting responses, especially with regard to the concept maps in Part 2.

The researcher (and also teacher and author of this paper) invited the students to provide general, informal comment on their answers and the SRE. Several similar themes emerge from each of these interviews. Though these themes inter-relate, each will be discussed below in light of how they relate to the research questions.

\section{Findings and Discussion}

How effective is the SRE in complementing the goals of the course? At one point in the interview with Student $A$, the following exchange takes place:

A: I could see each form of each essay, or how can I say?

T: Genre?

A: Yeah, yeah, yeah! So email is always like this, and poem is so simple but has very deep meaning, so I could know form and afterwards I always think deeply and meaning. 
When asked if this ability to recognise features of certain genres was the result of classwork or the SRE, Student A answers, "mainly class, but seeing many genre or this kind is from standard reading exercise." To this end, the SRE seems to have been useful in enabling genre awareness in the students. Student $C$ seems to agree, as she comments in her interview that "having too many genre is good . . . because I was surprised this one, this email . . I I thought it's email but actually it's spam."

Interestingly, none of the students in the class were able to recognise the spam email (asking for bank details) for what it is, and all took it to be a genuine request for help. When asked why this is the case, all three students give similar answers. For example, Student A comments that she "didn't expect you will give us spam." Usually, she would "realise this is strange," but she "thought this was assignment." Similarly, Student B remarks that "you gave me this so I didn't think this is spam email." Student C also states she can normally identify spam, but in an academic context, her "focus is different . . . I think I couldn't notice it's spam because I think it's assignment and just text."

Clearly they were not able to correctly identify this text when doing the SRE due to their contextual expectations. This does not necessarily suggest that the SRE was a failure in getting students to reflect on field, tenor and mode, as Student $C$ suggests that the eventual realisation in itself was useful: "I think if we have this kind of shock we will remember."

Student $A$ believes that the exercise influenced how she and her classmates went about their regular classwork in the FL class, using her classmate (" $\mathrm{X}$ ") as an example of a student who, as a result of repeatedly completing the SRE, began to reflect more on language use: "because for example $\mathrm{X}$ always says this is formal or informal language, we always discuss language choice, so helped class." Student A is convinced the SRE has not only benefited her classwork, but changed the way she generally thinks about language and text: "Until starting this I didn't try to read deeply," but now she reflects on "intended audience" and "appropriate language use ... I didn't think any of this before doing this." Generally, doing the SRE has enabled her to "think complicated," which "was very useful for me." Whenever she reads, whether in English or Japanese, "after understanding, I try to think deeply."

Similarly, Student B says "I didn't care about texts' tone before," but after completing the SRE a few times, now "I care this kind of thing ... maybe it helped me understanding ... what the author wants to say . . like why did he or she use academic words, like deeper reading." She has "started to think about tone, topic, ideas" whenever she reads.

Student C, however, does not believe the exercise has changed the way she thinks about field, tenor, and mode, claiming she "didn't focus on authorial intention," and that she continues to "just focus on each word." This opinion may not be accurate, as she was almost alone in being able to spot the use of irony in a poem and made imaginative use of concept maps in Part 2. Whether this is due to her own natural ability or the effect of the SRE, overall these interviews seem to illustrate that the exercise was relatively effective in complementing the goals of the FL course.

What effect does it have on students' reading ability? Student A believes the SRE "gave me process of reading in English ... it is useful." She qualifies why this trained "process" is important; now whenever she reads, she "always try to find context ... to read easily and this is because I did standard reading exercise." The student refers to any text she reads, not just assigned homework, when she describes this newly-acquired "process" of reading. She begins by "skimming" and then predicts content based on "key words," which aids her in 
understanding the whole text. She states that she feels she "can imagine without dictionary."

Student B is also of the opinion that the exercise has improved her reading skills and strategies:

Because of this assignment I was able to learn how to read texts ... so key words, phrases ... these words are important to read texts... We have to understand main ideas to read... Thanks to this paper, assignment, I was able to read better than before.

These two students' analyses of their reading abilities suggest, in this regard, the SRE is a success. Their reading ability has improved in relation to Scott et al.'s (1984) goal, stated earlier, to enable learners to acquire the ability to guess the meaning of words from context.

Student C's analysis is more complicated: "When I read a text I didn't see, I try to skim a lot of information." She claims she only does this now as a result of the SRE. As with Students A and B, the exercise has taught her a useful process for reading: "After skimming, I have to write down this. I have to read again and in more detail so I can understand more." However, it perhaps has not deterred her obsession with understanding every word: "I'd like to understand whole sentence and one word, one word... There are many unknown words so I have to research the words' meaning" using a dictionary. When asked why she still has this obsession, Student C replies that it is simply "my character."

This preoccupation with detail at the word level explains the excessive length of time she often spent doing the SRE, which in turn has had a detrimental effect on her motivation. Other students had similar complaints. Student B, for example, describes the exercise as being "helpful, but takes time." Scott et al. (1984) express similar quandaries; despite mostly positive feedback from their participants, they "have complained that it is quite a long exercise, and takes time to do" (p. 117).

It was emphasised to FL students that the SRE should take approximately 40 minutes at most. Nevertheless, Student B claims she typically spent from 40 minutes to 1 hour on each assigned reading. Student $C$ states that she did not like the SRE primarily "because it takes much time," spending an hour or more on each assigned text. Interestingly, however, when she attempted to save time, for example, by drawing pictures in Part 2 to represent her understanding of irony in a poem, her answers were more insightful.

With this in mind, teachers need to emphasise the importance of focusing more on general meaning and spending no longer than 40 minutes on each reading, and perhaps the exercise itself needs additional editing.

Despite Student C's stated dislike of doing the exercise, the quality of her work was amongst the best in the class, and she acknowledges that "I know it's useful for me... because if I don't have this assignment I don't read texts so much, and I think reading speed is faster than before." Overall, the SRE seems to have had a positive effect on student reading ability.

What, if any, are the benefits of a repeated activity? Student A unequivocally in believes in the positive effects of repetition, stating "doing many times was so useful." For her, the SRE was initially difficult; she "didn't get used to this" at first. "But now I get used to this and think more deeply. But it is also difficult! Do you understand?" That is, the exercise was arduous to become accustomed to, but then became easier and yet at the same time more intellectually challenging. Student B similarly believes the routine of the repeated activity was beneficial: 
"This standard reading exercise is habit for me, so... it's helpful for me."

Student $C$ is more ambiguous. She agrees that the nature of a repeated set of questions meant the task "became easier" each time, commenting that, "at first I could not understand this text is formal or informal, but finally I can choose easily." The "good point" for her with regard to the use of the same activity every week is that "we can compare with the other texts." This crossdiscourse comparison is useful for achievement of genre awareness, a stated aim of the FL course. However, for Student C, the "bad point is I think we always focus on the same points. I think sometimes we need different angle." She contradicts herself again upon reflection, concluding that "I think same question is better" than changing the questions every week.

A limited conclusion can be drawn here: although the SRE might initially prove difficult or seem monotonous, as it is habit-forming and builds genre awareness in students, the effect of the repeated activity is largely positive.

How can the SRE be improved for the future? While the majority of feedback was positive, all three students provide plenty of suggestions for improvement. Once again, interviewees' responses prove most enlightening when they touch upon similar points.

Both Students A and B suspect the installed habits and deep-reading that result from doing the SRE might have a detrimental effect "when I have to read so quickly, for example, exam or TOEFL" (Student A). The SRE, while "useful," is "sometimes too complicated," and in a "TOEFL test we have time limit" (Student B).

When asked which parts they found least useful, Student A suggests Part 1, Question 5 (Were your predictions in Questions 2 to 4 correct?) and Part 4, Question 1 (How interesting was the text?). One might assume students would find choosing point on a rating scale cognitively less demanding, but Student A explains that she "couldn't decide how much I could understand," and that the word "interesting'... has too many meanings." For the same reason, Student B never answers Part 1, Question 5: "Every time... I don't know" (how correct her predictions were), and gives a similar reason for her dislike of Part 4, Question 2 (As a very rough approximate, how much of the text do you think that you understood?): "I don't know how much I was able to understand."

Student $C$ regards the whole Reflection section as "the least useful... because it's not related to the contents and understanding" of the text. Echoing the concerns of the other two interviewees, she explains "this question is just interesting or boring, or how could I understand." She instead suggests the inclusion of a question asking "How fast" the text could be read as "it's related to understanding."

Student B logically suggests that the questions related to reflection and self-analysis would be easier after group feedback sessions in class, as she "wanted to compare with others." The value of these sessions that sometimes occurred after completion of the homework is another point upon which the students agree. Student B says that "listening to others' answers are really helpful... helped me a lot to think it another way... others' thinking, others' opinion so I can expand my ideas." Student C also appreciates the mutual reassurance and exchanging of ideas: "after we did this assignment we discussed in class... so, yeah I felt nervous... but finally I thought just say my opinion is okay, so relaxed." These sessions should take place more consistently. 
Student A proposes an additional creative activity where "students have to make short story from picture or something." This could be made into a blog activity, and could alternate with the SRE. Student $C$ suggests an additional question to aid students in recognising texts for what they are and overcome their expectations (as with the spam email): "Have you ever got this kind of email?" This question could be reformulated as "Have you ever seen this type of text before?" and added to Part 1.

\section{Conclusion}

On the whole, the utilization of the SRE has been a relative success. In the survey, over $79 \%$ rated the exercise as quite or very useful. This is not conclusive, as they may have felt some pressure to give positive answers for cultural reasons, although the survey was conducted anonymously.

All three interviewees rated it as useful and valuable, and two of them were very positive and seemed to enjoy the activity despite (or because of) its challenges. However, only interviewing three students, all of whom are highly motivated with good grades, obviously has its limitations. Nonetheless, many positives can be interpreted.

The SRE helped familiarise students with a large range of genres, encouraged them to think more deeply about language use, improved reading ability, and installed good reading habits, amongst many other potential benefits. There are aspects to consider for improvement. The area of concept maps will be discussed in a future paper. For now, considerations include reducing the length of time students spend on the activity, countering any negative impact on ability to read quickly in exams, alternating the exercise with more creative blogs, and making better use of digital media and multimodal forms of expression. There are solutions for these dilemmas, some suggested by the students themselves.

Finally, this study is useful for anyone who wishes their students to improve reading ability, especially where access to materials is compromised by budgets or time demands, as is often the case in some poorer nations. This study is a continuation of the work done by Scott et al. (1984), suggesting that the basic principle of a SRE is an effective one. If designed well, a simple list of questions that encourages students to think carefully and critically about text, used repeatedly with a large range of discourse types, is a worthwhile activity that produces many benefits and is an efficient learning tool.

\section{Author Note}

James Emmet Owens, English Department, Kanda University of International Studies, Chiba, Japan.

Correspondence concerning this article should be addressed to James Emmet Owens, ELI, Kanda University of International Studies, 1-4-1 Wakaba, Mihama-ku, Chiba-shi, Chiba-ken, 261-0014, Japan. E-mail: james-o@kanda.kuis.ac.jp 


\section{References}

Byrnes, H., Crane, C., Maxim, H. H., \& Sprang, K. A. (2006). Taking text to task: Issues and choices in the curriculum construction. ITL - International Journal of Applied Linguistics, 152, 85-110. http://dx.doi.org/10.2143/ITL.152.0.2017864

Chaisiri, T. (2010). Implementing a genre pedagogy to the teaching of writing in a university context in Thailand. Language Education in Asia, 1, 181-199. Retrieved from http://dx.doi.org/10.5746/LEiA/10/V1/A16/Chaisiri

Hyland, K. (2007). Genre pedagogy: Language, literacy and L2 writing instruction. Journal of Second Language Writing, 16(3), 148-164. http://dx.doi.org/10.1016/j.jslw.2007.07.005

Johns, A.M. (2008). Genre awareness for the novice academic student; An ongoing quest. Language Teaching, 41(2), 237-252. http://dx.doi.org/10.1017/S0261444807004892

Nelson, M. E. (2008). Multimodal synthesis and the voice of the multimedia author in a Japanese EFL context. Innovation in Language Learning and Teaching, 2(1), 6582. http://dx.doi.org/10.1080/17501220802158826

Paltridge, B. (2002). Genre, text type, and the English for academic purposes (EAP) classroom. In A. M. Johns (Ed.), Genre in the classroom: Multiple perspectives (pp. 73-90). Mahwah, NJ: Lawrence Erlbaum Associates.

Scott, M., Carioni, L., Zanatta, M., Bayer, E., \& Quintanilha, T. (1984). Using a 'standard exercise' in teaching reading comprehension. English Language Teaching Journal, 38(2), 114-1 20. http://dx.doi.org/10.1093/elt/38.2.114

Thompson, G. (2012). Intersubjectivity in newspaper editorials: Construing the reader-in-thetext. English Text Construction, 5(1), 77-100. http://dx.doi.org/10.1075/etc.5.1.05tho 


\section{Appendix A}

\section{Scott et al.'s (1984, p. 116) Standard Reading Exercise (Figure 1. Standard Exercise translated from Portuguese)}

1. Read only the title of your text. Predict and write down at least five vocabulary items-key words-which you expect to see in the text. Use a dictionary if necessary. The key words can be noted down in English or in Portuguese.

2. Skim the text quickly (maximum one minute), looking for key words in the text. Use all the typographical indications, your previous knowledge, cognates, and repeated words. Now write down, in no more than fifteen words, the main theme of the text.

Re-read the text as often as necessary to answer the following questions:

3. What seems to be the author's main intention: to persuade you or just to inform you?

4. Write down any words which look important in the text (key words) which you did not know before reading it. Beside each one, write down your idea of what it probably means.

5. Write down the main idea of each paragraph, using only one sentence for each main idea. If the text consists of more than seven paragraphs, write down the main idea of each main section. Avoid translating, and try not to mention insignificant details.

6. Divide the text into sections. Is there an introduction? If so, where does it end? Is there a conclusion? If so, where does it start? Explain your answer.

7. Write one sentence reporting something which you learned from the text.

8. Critical reaction: whose interests does this text reflect? Which country, which social class, or which institution? Who would find the publication of this text desirable? Is the information in this text applicable to your own situation?

9. Indicate your interest in this text, using a scale from 1 to 5 ( $5=$ very interesting, $1=$ very boring).

10. How many times did you need to use a dictionary to answer the questions so far?

11. Write down the number of each paragraph which you feel you couldn't understand properly, or aren't sure you understood.

12. Try to work out why you found the paragraphs you listed in the last question so difficult. What was the main reason?-

a. lack of previous knowledge of the topic

b. a grammatical problem (which one?)

c. inefficient reading strategies

d. difficulty in separating main points from details

e. difficulty in identifying the introduction or conclusion

etc.

13. Now estimate your comprehension of the text (e.g. 50 per cent, 80 per cent). 


\section{Appendix B \\ Standard Reading Exercise Used in \\ the Foundational Literacies Advanced Stream Course}

\section{Standard reading exercise (to be completed every week with a different text)}

\section{Part 1 - Predicting}

1. Skim through the text. Do you notice any key words or phrases? Write them down.

2. What do you think is the main idea (topic) in this text?

3. What do you think the genre of the text will be?

4. What do you think the tone of this text is generally:

Academic

Formal

Argumentative

Informal

Literary

Mixed

Other:

NOW, READ CLOSELY THROUGH THE TEXT

Then answer the following questions.

5. Were your predictions in Questions 2 to 4 correct?

\begin{tabular}{lllllll} 
& 1 & 2 & 3 & 4 & 5 & \\
\hline No - I got everything wrong :( & $\bigcirc$ & $\bigcirc$ & $\bigcirc$ & $\bigcirc$ & $\bigcirc$ & Yes - completely correct! \\
\hline
\end{tabular}

\section{Part 2 - Reading for content}

Read the text in more detail, and create a "concept map" showing 1) the organization of ideas within the text (e.g. give each paragraph a sub-heading); 2) what you think the author's purpose is; and 3) the tone of the text. Your teacher will show you an example framework for this, but you have freedom to draw this map in any way that helps you to understand. Try to include reasons or examples in your notes. 


\section{Part 3 - Text in context}

1a. What kind of text MIGHT this be? *Choose only one.

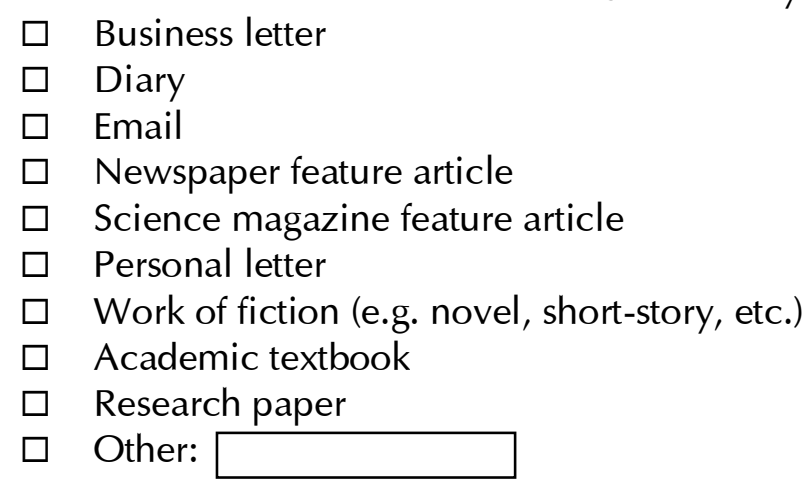

1b. Why do you think it could be one of these texts?

2. Who do you think the intended audience of the text is? What clues are there in the text that show this?

3. All language use (e.g., vocabulary, tone, sentence length) reflects a choice. Why does the writer choose to write in this style?

\section{Part 4 - Reflection}

1. How interesting was the text?

\begin{tabular}{lllllll} 
& 1 & 2 & 3 & 4 & 5 & \\
\hline very boring & $\bigcirc$ & $\bigcirc$ & $\bigcirc$ & $\bigcirc$ & $\bigcirc$ & very interesting \\
\hline
\end{tabular}

2. As a very rough approximate, how much of the text do you think that you understood? (e.g., $10 \%, 50 \%, 90 \%)$

3. If you found the text difficult to understand, what was the main reason? *Choose one:
$\square$ It wasn't difficult
$\square \quad$ Lack of previous knowledge of the topic
$\square \quad$ A grammar problem
$\square$ Too many new words
$\square$ Inefficient reading strategies
$\square$ Difficulty in separating main points from details
$\square$ Difficulty in identifying the introduction or conclusion
$\square$ Other:

4a. If you answered "A grammar problem" in Q4, AND you think you know what grammar point is that made it difficult to understand the text, please elaborate here. Note (1) If you didn't have a grammatical problem, write n/a. Note (2) If you answered "A grammar problem" in Q4, BUT you're unsure what the grammar problem is, please write "unsure" below. 